\title{
Trehalose: an intriguing disaccharide with potential for medical application in ophthalmology
}

This article was published in the following Dove Press journal:

Clinical Ophthalmology

9 May 201I

Number of times this article has been viewed

\author{
Jacques Luyckx' \\ Christophe Baudouin ${ }^{2}$ \\ IThea Laboratories, Clermont-Ferrand, \\ ${ }^{2}$ Quinze-Vingts National Hospital and \\ Vision Institute, University Paris 6, \\ Paris, France
}

\begin{abstract}
Trehalose is a naturally occurring disaccharide comprised of two molecules of glucose. The sugar is widespread in many species of plants and animals, where its function appears to be to protect cells against desiccation, but is not found in mammals. Trehalose has the ability to protect cellular membranes and labile proteins against damage and denaturation as a result of desiccation and oxidative stress. Trehalose appears to be the most effective sugar for protection against desiccation. Although the exact mechanism by which trehalose protects labile macromolecules and lipid membranes is unknown, credible hypotheses do exist. As well as being used in large quantities in the food industry, trehalose is used in the biopharmaceutical preservation of labile protein drugs and in the cryopreservation of human cells. Trehalose is under investigation for a number of medical applications, including the treatment of Huntington's chorea and Alzheimer's disease. Recent studies have shown that trehalose can also prevent damage to mammalian eyes caused by desiccation and oxidative insult. These unique properties of trehalose have thus prompted its investigation as a component in treatment for dry eye syndrome. This interesting and unique disaccharide appears to have properties which may be exploited in ophthalmology and other disease states.
\end{abstract}

Keywords: desiccation, trehalose, cells, disaccharide

\section{Introduction}

Trehalose, a naturally occurring alpha-linked disaccharide formed of two molecules of glucose (Figure 1), was isolated in the mid 19th century by the French chemist, Marcellin Berthelot, from Trehala manna, a sweet substance obtained from the nests and cocoons of the Syrian coleopterous insect (Larinus maculatus, Larinus nidificans) which feeds on the foliage of a variety of thistles. It has been used as a foodstuff, and is also called "nest sugar". In the intervening years, there has been considerable research on the biological and chemical properties of trehalose and on its role in living organisms. A recent PubMed search yielded more than 4600 references for the search term "trehalose", including comprehensive reviews of the biology of trehalose in plants, insects, and other species. ${ }^{1-3}$

Trehalose has found a number of practical and commercial applications, particularly in the food and cosmetic industries ${ }^{2}$ and as an excipient in pharmaceutical formulations, and is prepared in bulk quantities by enzymatic conversion of starch, primarily in Japan.

\section{Function of trehalose in trehalose-producing organisms}

One of the most intriguing characteristics of trehalose is that it is synthesized by many living organisms, including insects, plants, fungi, and micro-organisms, ${ }^{3}$ as a response 


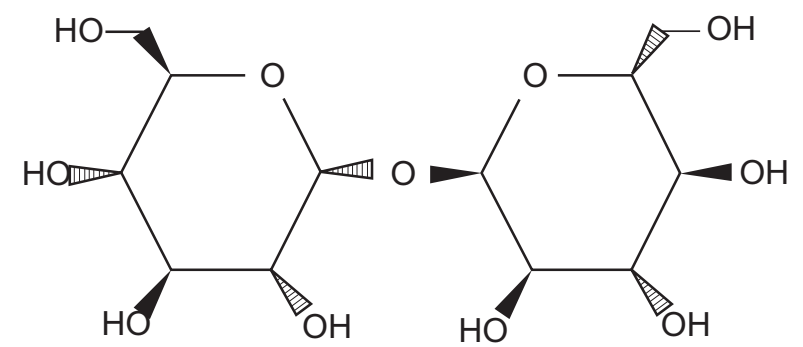

Figure I Structure of trehalose. Registry number: 99-20-7; Molar mass: $342.296 \mathrm{~g} / \mathrm{mol}$ (anhydrous); $378.33 \mathrm{~g} / \mathrm{mol}$ (dihydrate); molecular structure: $\alpha$-D-glucopyranosyl $\alpha$-D-glucopyranoside ( $\alpha, \alpha$-trehalose).

to prolonged periods of desiccation. This very useful property, known as anhydrobiosis, confers on an organism the ability to survive almost complete dehydration for prolonged periods and subsequently reanimate. In many species, such anhydrobiosis is believed to be due to the interaction between trehalose, water, and cell structures that permit survival of the organism during periods of desiccation. Trehalose is not synthesized by mammals.

\section{Trehalose and protection from dehydration}

A "water replacement" hypothesis to explain the role of trehalose in anhydrobiosis has been proposed. This hypothesis suggests that trehalose replaces water in the desiccated organism by hydrogen bonding interactions with polar groups on membrane lipids and proteins., ${ }^{4,5}$

An alternative hypothesis has suggested that trehalose modifies the tetrahedral hydrogen-bond structure of water and rearranges the remaining water molecules around biological structures. This reduces the amount of water at the interface of biomacromolecules and membranes, in turn avoiding structural fluctuations and damage to cellular organelles during dehydration. ${ }^{6}$ In addition, some physical chemistry properties of trehalose in more concentrated solution are particularly beneficial during desiccation; on drying it has a lower tendency to form crystals that can damage cell organelles than other disaccharides, but instead is thought to form a gel phase that might contribute to resilience to cellular desiccation. ${ }^{7}$

\section{Trehalose and membrane lipid bilayers}

Lipid (more correctly phospholipid) bilayers are essential components of cells. As well as forming a physical barrier between the contents of the cell and its environment, key intracellular organelles are formed from lipid bilayers. A degree of hydration is essential for the integrity of lipid bilayers. Desiccation causes irreversible damage to the integrity of the cell and, in particular, results in lipid phase transition, a change that trehalose has been shown to inhibit. Trehalose thus maintains the lipid in the liquid phase in the absence of water. ${ }^{8}$ It has been shown that stabilization of lipid systems with trehalose enables the membranes to retain both their functional properties (eg, calcium transport, ATPase activity) and cellular contents. ${ }^{9}$ In the great majority of studies, trehalose is the most effective saccharide for maintaining the integrity of phospholipid bilayers. ${ }^{4}$

\section{Trehalose and labile proteins}

Trehalose also preserves labile cellular proteins against desiccation, probably by interacting directly with the dehydrated protein via hydrogen bonding between its hydroxyl groups and polar residues in the protein. Trehalose is an important protector of protein integrity, by limiting protein denaturation under heat stress, oxidant injury, and anoxia, ${ }^{10}$ and is the most effective disaccharide for stabilizing proteins during desiccation. ${ }^{4}$ The various theories to explain the exceptional properties of trehalose in stabilizing proteins have been recently reviewed. ${ }^{11}$

The ability of trehalose to stabilize fragile proteins and protect them from denaturation has been exploited in biopharmaceutical formulations, notably monoclonal antibodies, including ranibizumab and bevacizumab which are formulated in solution, or trastuzumab which is subjected to freeze-drying. The ability of trehalose to stabilize aggregationprone protein molecules is under investigation as a possible approach in the treatment of polyglutamine diseases, such as Huntington's chorea ${ }^{12,13}$ and Alzheimer's disease. ${ }^{14,15}$

\section{Trehalose and oxygen radicals}

The evidence thus far suggests that trehalose can protect against desiccation, both in lower organisms and also in mammalian cells. In addition, evidence is accumulating that trehalose has a role to play in protecting cells against oxidative stress. A new role for trehalose in protecting cells against oxygen radicals has been postulated. Yeast cells exposed to mild heat shock or proteasome inhibitors respond with an accumulation of trehalose, coincident with a marked increase in viability, when exposed to a free radical-generating system. Moreover, this improvement in cellular viability is absent in mutant strains of yeast cells that lack the capability to synthesize trehalose. These findings suggest that trehalose has a role in protecting cells and their components from oxidative damage. ${ }^{16}$

When oxidative stress was provoked in yeast cells by the application of menadione, a source of superoxide, cell survival was markedly improved by pretreatment with trehalose or by heat treatment, which increases trehalose accumulation. ${ }^{17}$ 
The improvement in cell survival was apparently correlated with reduced lipid peroxidation. Therefore, it would appear that the role of trehalose is to protect cells, and lipid bilayers in particular, from oxidative damage.

\section{Effects of trehalose in mammalian cells}

Whilst convincing evidence indicates that accumulation of trehalose in the cytoplasm of many lower organisms functions to protect proteins and membranes from denaturation caused by desiccation, heat, and oxidative stress, ${ }^{8}$ mammalian cells do not have the ability to synthesize trehalose, although humans can metabolize ingested trehalose as a result of the trehalase enzyme in the intestinal villi.

The ability of trehalose to stabilize membranes and proteins has obviously raised interest in the potential protective effects of trehalose when administered to mammalian cells. For example, trehalose has been investigated in the cryopreservation of human hepatocytes for cell transplantation. ${ }^{18}$ Supplementation of standard cryopreservation solution with trehalose significantly improved post-thaw cell viability, metabolism, and plating efficiency, suggesting that trehalose makes a useful contribution to hepatocyte cryopreservation. Similarly, when introduced into human oocytes by microinjection, trehalose was shown to confer significant protection to the oocyte cells against the stresses associated with freezing. Indeed, whilst the majority of trehalose-treated cells survived freezing to $-60^{\circ} \mathrm{C}$, none of the untreated cells survived this temperature. ${ }^{19}$

\section{Protective effects of trehalose on desiccated epithelial cells}

Trehalose protects desiccated cultured corneal cells from death. Following preincubation with various concentrations of trehalose or a control medium, cultured human corneal cells were left to dry for 30 minutes. The percentage of dead cells was markedly and significantly lower in cells preincubated with trehalose than in those preincubated in a control medium. ${ }^{20}$ This finding was confirmed in an analogous ex vivo study carried out in enucleated porcine eyes. Following incubation with maltose, sucrose, trehalose, or saline, the corneal epithelial surfaces were allowed to dry. The tissue incubated with trehalose was visibly smoother under dissecting microscopic observation, and there were significantly fewer pits observed under atomic force microscopy. ${ }^{21}$

\section{Trehalose in ophthalmology}

As the two above mentioned laboratory studies convincingly show, trehalose can confer desiccation tolerance to mammalian corneal cells, just as it does to cells of lower organisms. Therefore, it was interesting to investigate whether such a protective effect could also be demonstrated in vivo. This was evaluated in an experimental model of murine dry eye..$^{22}$ Briefly, mice were exposed to controlled low-humidity airflow and temperature for 21 days. This resulted in a severe evaporative dry eye syndrome displaying biological and morphologic changes similar to those in humans. This dry eye environment appears to upregulate apoptosis on the ocular surface. Following exposure to the evaporative environment, the mice were randomized to receive topical administration of $30 \mathrm{mg} / \mathrm{mL}$ trehalose ophthalmic solution (Thealoz ${ }^{\circledR}$, Laboratoires Théa, Clermont-Ferrand, France) or a phosphate-buffered saline control solution during a further 14 days' exposure to the evaporative environment. Trehalose administration resulted in significant improvements on the ocular surface (cornea and conjunctiva), including reduction of corneal fluorescein staining area, decrease of ruffling and desquamating cells on the apical corneal epithelium, as well as a decrease in the number of apoptotic cells in the ocular surface epithelium when compared with controls, an effect comparable with that obtained in homologous mouse blood serum (Figure 2). ${ }^{23}$

In a subsequent and as yet unpublished study using this same model of dry eye, the same investigators compared topical trehalose with topical cyclosporin $0.05 \%$ ophthalmic solution. ${ }^{24}$ Consistent with previous reports, ${ }^{25}$ topical cyclosporin significantly reduced epithelial apoptosis on the ocular surface and protected against goblet cell loss in this experimental murine model of keratoconjunctivitis sicca. Trehalose produced some of the same responses as

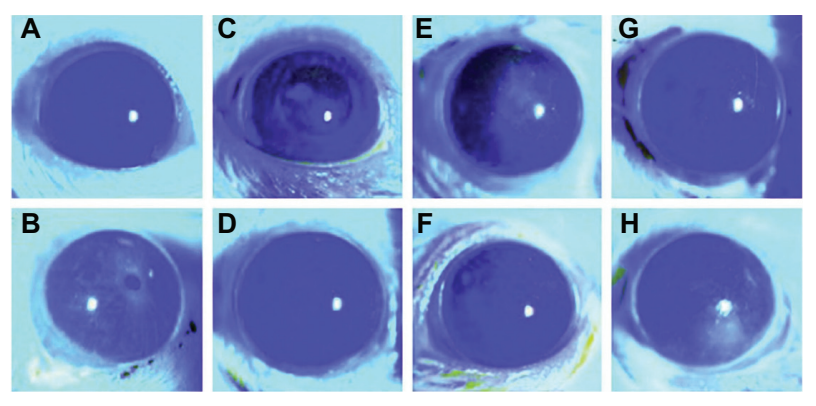

Figure 2 Trehalose protects against corneal damage due to desiccation. Corneal fluorescein staining following exposure to a desiccant environment. Mice were exposed to a desiccating environment for 21 days and then received treatment with phosphate-buffered saline, trehalose eyedrops, or mouse serum eyedrops for 14 days. A) Control mice, B) 21 days desiccation without treatments, C) and D) seven and I 4 days' desiccation with trehalose treatment, E) and F) seven and I4 days desiccation' with mouse serum treatment, $\mathbf{G}$ ) and $\mathbf{H}$ ) seven and I 4 days' desiccation with phosphate-buffered saline treatment.

Copyright@ 2010. Elsevier. Reproduced with permission from Chen W, Zhang X, Liu M, et al. Trehalose protects against ocular surface disorders in experimental murine dry eye through suppression of apoptosis. Exp Eye Res. 2009;89: 3||$-3 \mid 8^{23}$ 
cyclosporin upon topical application and maintained corneal health, but was also more effective than cyclosporin at reducing epithelial apoptosis on the ocular surface. Topical cyclosporin significantly reduced the number of active CD4positive T cells, while trehalose had no such effect, suggesting that the mechanism of trehalose in this model is more that of a surface protectant than of a pharmacological agent. Additional experiments are ongoing for trehalose in the murine dry eye model to determine its effects on desiccating stress at the corneal barrier and the expression of metalloproteinases. ${ }^{26}$

The damage done to corneal tissue by ultraviolet B irradiation occurs via an oxidative pathway in which corneal antioxidants, which protect the cornea from highly reactive oxygen and nitrogen species, are depleted. Therefore, the potential protective effect of trehalose in rabbit eyes submitted to ultraviolet B rays has been investigated. ${ }^{27}$ During irradiation with ultraviolet $B$ at a daily dose equivalent to five hours of exposure of the human cornea to ultraviolet B from sunlight, trehalose was applied as $30 \mathrm{mg} / \mathrm{mL}$ eye drops to the right eye while buffered saline was applied to the left eye. In trehalosetreated eyes, there was less corneal edema (corneas were more transparent), and much less intracorneal inflammatory cell infiltration, and neovascularization was suppressed (Figure 3). Expression of nitric oxide synthases leading to the formation of nitric oxide was reduced and formation of cytotoxic peroxynitrite decreased. Aldehyde dehydrogenase 3A1 (an antioxidant enzyme) expression was inhibited to a lesser extent and corneal
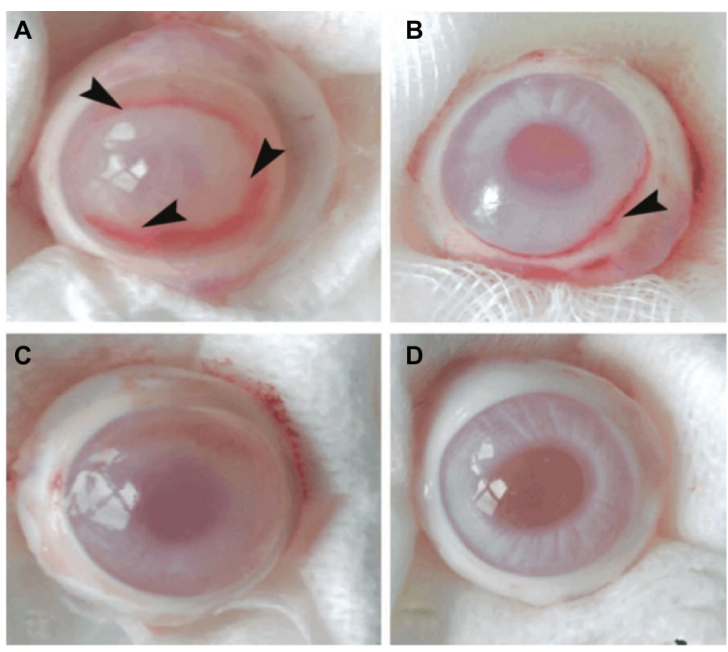

Figure 3 Rabbit eyes following irradiation with ultraviolet for four days, with concurrent treatment of trehalose or buffered saline. A) Corneal vascularization and loss of transparency in saline-treated eye; B) and C) eyes treated with trehalose, showing less vascularization and retention of transparency; and D) normal (nonirradiated) cornea.

Copyright@ 2010. Histology and Histopathology. Reproduced with permission from Čejková J, Čejka Č,Ardan J, Širc J, Michálek J, Luyckx J. Reduced UVB-induced corneal damage caused by reactive oxygen and nitrogen species and decreased changes in corneal optics after trehalose treatment. Histol Histopathol. 2010;25:1403-1414. ${ }^{27}$ epithelial apoptosis was greatly attenuated. Therefore, in this model, topical trehalose effectively reduced oxidative damage of the cornea evoked by ultraviolet B rays and protected against the development of an oxidative environment.

\section{Trehalose use in humans}

Trehalose is widely distributed in nature, including in many species that have long been incorporated into human foodstuffs. Moreover, the finding that the human body has the trehalase enzyme (which cleaves one molecule of trehalose into two molecules of glucose) in cells of the intestinal villi and kidney brush border attest to the fact that humans have long been exposed to this disaccharide.

Trehalose is widely used as an ingredient in processed foodstuffs, is authorized in the European Union under Regulation (EC) 258/97 (commission decision of 25 September 2001), and is generally recognized as safe by the US Food and Drug Administration. The same year, the Joint Expert Committee on Food Additives (formed by the United Nations Food and Agriculture Organization and the World Health Organization), assessed the safety of trehalose and gave it a favorable evaluation. ${ }^{28}$

There are currently four injectable pharmaceutical preparations that contain trehalose as an excipient, ie, Avastin ${ }^{\circledR}$ and Herceptin ${ }^{\circledR}$ (Roche), Advate ${ }^{\circledR}$ (Baxter), and Lucentis ${ }^{\circledR}$ (Novartis), thus confirming that trehalose can be used safely as an ingredient in injectable formulations. Two of these preparations (Avastin and Lucentis) are administered to the human eye by intravitreal injection.

Trehalose is also an important component of Kyoto solution. Recent studies suggest that the use of this preparation in the preservation of pancreatic tissue improves clinical outcomes in transplantation surgery. ${ }^{29}$ Although the relevant clinical studies are outside the scope of this review, trehalose has been shown to be more effective in improving objective signs of dry eye compared with hyaluronan and hydroxyethylcellulose solutions in patients with moderate or severe dry eye. . $^{30,31}$

\section{Conclusion}

Trehalose, a naturally occurring disaccharide, is widely distributed throughout the biological world and is found in plants, algae, fungi, yeasts, bacteria, insects, and other invertebrates, in which it plays a major role in anhydrobiosis, desiccation, and perhaps in the protection against oxidative and other stresses. The mechanism by which trehalose provides such protection has not been fully elucidated, but probably involves stabilization of phospholipid bilayers and labile proteins, amongst other processes. 
Although trehalose is not present in mammals, recent studies in cultured mammalian cells as well as ex vivo and in vivo studies show that trehalose can protect mammalian tissues from desiccation as well as oxidative stress. In particular, the findings of in vivo models of dry eye in mice or in ultraviolet B-induced keratitis in rabbits showing that topically applied trehalose can exert a significant protective effect on the ocular surface are notable. Trehalose is not a new entity in the pharmaceutical arena. It has already been used as an excipient in injectable protein drugs and is widely employed as a protector in freeze-dried oocytes for in vitro fertilization. These findings suggest that trehalose may be worthy of investigation as a potential agent for the protection of the ocular surface in dry eye syndrome in humans. The results of studies to date are encouraging.

\section{Disclosure}

Dr Baudouin is a consultant to Laboratories Théa and has received unrestricted research grants from them. Dr Luyckx is an employee of Laboratories Théa.

\section{References}

1. Iturriaga G, Suárez R, Nova-Franco B. Trehalose metabolism: From osmoprotection to signaling. Int J Mol Sci. 2009;10:3793-3810.

2. Richards AB, Krakowka S, Dexter LB, et al. Trehalose: A review of properties, history of use and human tolerance, and results of multiple safety studies. Food Chem Toxicol. 2002;40:871-898.

3. Elbein AD. The metabolism of alpha, alpha-trehalose. Adv Carbohydr Chem Biochem. 1974;30:227-256.

4. Crowe JH. Trehalose and anhydrobiosis: The early work of J. S. Clegg. J Exp Biol. 2008:2899-2900.

5. Leidy C, Gousset K, Ricker J, et al. Lipid phase behavior and stabilization of domains in membranes of platelets. Cell Biochem Biophys. 2004;40:123-148.

6. Teramoto N, Sachinvala ND, Shibata M. Trehalose and trehalose-based polymers for environmentally benign, biocompatible and bioactive materials. Molecules. 2008;13:1773-1816.

7. Leopold AC. Membranes, Metabolism, and Dry Organisms. Ithaca, NY: Cornell University Press; 1986.

8. Elbein AD, Pan YT, Pastuszak I, Carroll D. New insights on trehalose: A multifunctional molecule. Glycobiology. 2003;13:17R-27R.

9. Crowe LM, Mouradian R, Crowe JH, Jackson SA, Womersley C. Effects of carbohydrates on membrane stability at low water activities. Biochim Biophys Acta. 1984;769:141-150.

10. Chen Q, Haddad GG. Role of trehalose phosphate synthase and trehalose during hypoxia: From flies to mammals. J Exp Biol. 2004;207: 3125-3129.

11. Jain NK, Roy I. Effect of trehalose on protein structure. Protein Sci. 2009;18:24-36.

Clinical Ophthalmology

\section{Publish your work in this journal}

Clinical Ophthalmology is an international, peer-reviewed journal covering all subspecialties within ophthalmology. Key topics include: Optometry; Visual science; Pharmacology and drug therapy in eye diseases; Basic Sciences; Primary and Secondary eye care; Patient Safety and Quality of Care Improvements. This journal is indexed on Submit your manuscript here: http://www.dovepress.com/clinical-ophthalmology-journal
12. Tanaka M, Machida Y, Niu S, et al. Trehalose alleviates polyglutaminemediated pathology in a mouse model of Huntington disease. Nat Med. 2004; 10:148-154.

13. Yang $C R, Y u$ RK. Intracerebral transplantation of neural stem cells combined with trehalose ingestion alleviates pathology in a mouse model of Huntington's disease. J Neurosci Res. 2009;87: 26-33.

14. Izmitli A, Schebor C, McGovern MP, Reddy AS, Abbott NL, de Pablo JJ. Effect of trehalose on the interaction of Alzheimer's A $\beta$-peptide and anionic lipid monolayers. Biochim Biophys Acta. 2011;1808:26-33.

15. Reddy AS, Izmitli A, de Pablo JJ. Effect of trehalose on amyloid beta(29-40)-membrane interaction. J Chem Phys. 2009;131:085101

16. Benaroudj N, Lee DH, Goldberg AL. Trehalose accumulation during cellular stress protects cells and cellular proteins from damage by oxygen radicals. $J$ Biol Chem. 2001;276:24261-24267.

17. Herdeiro RS, Pereira MD, Panek AD, Eleutherio EC. Trehalose protects Saccharomyces cerevisiae from lipid peroxidation during oxidative stress. Biochim Biophys Acta. 2006;1760:340-346.

18. Katenz E, Vondran FW, Schwartlander R, et al. Cryopreservation of primary human hepatocytes: The benefit of trehalose as an additional cryoprotective agent. Liver Transpl. 2007;13:38-45.

19. Eroglu A, Toner M, Toth TL. Beneficial effect of microinjected trehalose on the cryosurvival of human oocytes. Fertil Steril. 2002;77: $152-158$.

20. Matsuo T. Trehalose protects corneal epithelial cells from death by drying. Br J Ophthalmol. 2001;85:610-612.

21. Izawa Y, Matsuo T, Uchida T, Shimamura K, Ohtsuki H. Atomic force microscopy observation of trehalose-treated and dried corneal epithelial surface. Cell Preserv Technol. 2006;4:117-122.

22. Chen W, Zhang X, Zhang J, et al. A murine model of dry eye induced by an intelligently controlled environmental system. Invest Ophthalmol Vis Sci. 2008;49:1386-1391.

23. Chen W, Zhang X, Liu M, et al. Trehalose protects against ocular surface disorders in experimental murine dry eye through suppression of apoptosis. Exp Eye Res. 2009;89:311-318.

24. Chen W. The prophylactic efficacy of trehalose compared with CsA for treatment of murine dry eye induced by ICES. Laboratoires Théa. Data on file; 2009.

25. Strong B, Farley W, Stern ME, Pflugfelder SC. Topical cyclosporine inhibits conjunctival epithelial apoptosis in experimental murine keratoconjunctivitis sicca. Cornea. 2005;24:80-85.

26. Chen W, Li JI, Zhang XB. Trehalose, anhydrobiosis for the eye. Acta Ophthalmol. 2010;88 Suppl:s246.

27. Čejková J, Čejka Č, Ardan J, Širc J, Michálek J, Luyckx J. Reduced UVB-induced corneal damage caused by reactive oxygen and nitrogen species and decreased changes in corneal optics after trehalose treatment. Histol Histopathol. 2010;25:1403-1414.

28. Abbott PJ, Chen J. Trehalose. WHO food additive series 46: Available at: htpp://www.inchem.org/documents/jecfa/jecmono/v46je05.htm. Accessed December 22, 2010.

29. Matsumoto S, Noguichi H, Shimoda M, et al. Seven consecutive successful clinical islet isolations with pancreatic ductal injection. Cell Transplant. 2010;19:291-297.

30. Matsuo T, Tsuchida Y, Morimoto N. Trehalose eye drops in the treatment of dry eye syndrome. Ophthalmology. 2002;109:2024-2029.

31. Matsuo T. Trehalose versus hyaluronan or cellulose in eyedrops for the treatment of dry eye. Jpn J Ophthalmol. 2004;48:321-327.

\section{Dovepress}

PubMed Central and CAS, and is the official journal of The Society of Clinical Ophthalmology (SCO). The manuscript management system is completely online and includes a very quick and fair peer-review system, which is all easy to use. Visit http://www.dovepress.com/ testimonials.php to read real quotes from published authors. 